\title{
Plasminogen activators and their inhibitors in synovial fluids from normal, osteoarthritis, and rheumatoid arthritis knees
}

\author{
Carolyn Belcher, Fiona Fawthrop, Rowena Bunning, Michael Doherty
}

\begin{abstract}
Objectives-To establish baseline concentrations of plasminogen activators and their inhibitors in normal knee synovial fluids, and to compare them with well characterised osteoarthritis (OA) and rheumatoid arthritis (RA) knee fluids. Methods-A total of 26 normal subjects, 71 patients with $O A$, and 17 patients with RA underwent knee aspiration. Patients with $O A$ were subclassified according to presence of nodal generalised OA (NGOA) and synovial fluid calcium pyrophosphate crystals. Clinical assessment of inflammation (graded 0-6) was undertaken in OA and RA patients. Plasminogen activator (PA), plasminogen activator inhibitor (PAI), and urokinase-type PA receptor (UPAR) antigen concentrations were determined by enzyme linked immunosorbent assay. The species of PAs present were determined by sodium dodecyl sulphatepolyacrylamide gel electrophoresis.

Results-Concentrations of all antigens (uPA, tissue-type PA (tPA), uPAR, and PAI-1), were significantly greater in RA than OA; those in OA were significantly greater than normal. The concentrations showed no direct association with clinically assessed inflammation of the knee. In normal fluids, no associations with age were observed. Antigen concentrations (uPA, tPA, and UPAR) in NGOA differed from those in other subclasses of $O A$, but the species of PA present did not appear to vary between disease groups. The predominant PA appeared to have identity with uPA.
\end{abstract}

Conclusion-Because of the greater concentrations of these antigens in $O A$ compared with normal fluids, $O A$ cannot be used as a surrogate normal control in studies of the PA/PAI system. Alteration of the PA/PAI system was confirmed in RA and $O A$ knee fluids, with greater changes evident in RA. The finding of different concentrations of PA antigens in NGOA compared with other $O A$ fluids further supports a different pathogenic mechanism in this subset.

(Ann Rheum Dis 1996; 55: 230-236)

Plasminogen activators (PAs) are serine proteases that convert the zymogen, plasminogen, to plasmin. There are two forms of PA: tissuetype (tPA) and urokinase-type (uPA); they are products of different genes, having different molecular weights and immunological reactivity, and differing in their affinity for fibrin. ${ }^{12}$

The PA system can have both direct and indirect effects on extracellular matrix degradation. Plasminogen activators have a direct role in the degradation of extracellular matrix glycoproteins, ${ }^{3}$ and plasmin, formed by activation of plasminogen, can degrade connective tissue components, including proteoglycans. ${ }^{45}$ The metalloproteases collagenase and stromelysin are also implicated in cartilage degradation, ${ }^{6}$ and plasmin can transform their latent forms, procollagenase and prostromelysin, into the active forms, ${ }^{78}$ which can then specifically attack the extracellular cartilage matrix.

The activity of UPA and tPA is regulated by specific plasminogen activator inhibitors (PAIs). Both PAI-1 and PAI-2 form stable complexes with tPA and uPA. PAI-1 is the main PAI in plasma $^{9}$ and is also bound to extracellular matrix, where it may regulate matrix breakdown. ${ }^{10}$ It is produced by endothelial cells, platelets, and other cells resident in the joint, such as synovial cells and chondrocytes. ${ }^{211} 12$ PAI-2 is produced by inflammatory cells such as monocytes and polymorphonuclear leucocytes, and also by chondrocytes and synovia cells. $^{21213}$ In common with PAI-1, it may regulate extracellular tissue remodelling. It is important to study PAIs, as the balance between PA and PAI concentrations is an important determinant of overall PA activity.

The presence of a cellular receptor for UPA was first demonstrated by Vassalli et al. ${ }^{14}$ The uPA receptor (UPAR) binds the proform and enzymatically active uPA with high affinity, ${ }^{15}$ focusing uPA activity on the cell surface and enhancing the rate of activation of pro-uPA and plasminogen activation. ${ }^{15} 16$ uPARs have been described on a variety of cell types, including monocytes, chondrocytes, and synovial cells. ${ }^{17} 18$ In addition, the number of uPARs appears to be increased on monocytes in RA, and on synovial cells and chondrocytes in OA. ${ }^{18} 19$

Few studies have examined the PA/PAI system in human joint fluids. Plasminogen activators have been detected in synovial fluid from patients with rheumatoid arthritis (RA) and osteoarthritis (OA). ${ }^{20-22}$ Kikuchi et $a l^{21}$ found that PAs could be detected in both types of arthritis, but concentrations were greatest in RA. Mochan et $a l^{20}$ also found a significantly 
greater PA activity in RA compared with OA, which they believed to be the result of an increase in PA antigen concentrations, rather than a decrease in PAI activity. Saxne et $a l^{22}$ found increases in uPA, PAI-1, and PAI-2 concentrations in RA compared with OA.

No data are currently available concerning normal synovial fluid concentrations of PAs or PAIs, or any possible associations with the age of the subject. Furthermore, no study has examined possible differences between subsets of $\mathrm{OA}$ or the relationship between PA/PAI concentrations and clinically assessed inflammation of the aspirated joint. The objectives of this study were therefore to establish baseline concentrations in normal knees, to examine possible age related changes, and to determine PA/PAI concentrations in well characterised $\mathrm{OA}$ and RA knees.

\section{Subjects and methods}

This study was approved by the local Research Ethics Committee.

\section{SUBJECTS}

Normal subjects had never experienced knee symptoms, had normal knees on clinical examination, and had no clinical evidence of peripheral joint OA or other joint disease. Knee radiographs were obtained in those older than 50 years, to exclude unsuspected mild OA or chondrocalcinosis.

Patients with symptomatic knee OA all had radiographic evidence of joint space reduction and bone response (osteophyte with or without sclerosis) in at least one compartment (medial or lateral tibiofemoral, patellofemoral). Full clinical examination, radiographic screening, and synovial fluid crystal analysis were used to assign these patients to OA subsets: pauciarticular, large joint $O A(\mathrm{OA})$-patients with isolated knee OA or with additional involvement of other large joints (hips, shoulders), but not hand joints; chronic pyrophosphate arthropathy (CPA) - knee OA with calcium pyrophosphate crystals identified in knee synovial fluid by compensated polarised light microscopy (with or without radiographic chondrocalcinosis of the knee); nodal generalised $O A$ (NGOA)-knee OA and coexistent Heberden's (with or without Bouchard's) nodes and radiographic evidence of interphalangeal OA affecting at least three rays of each hand.

Standing anteroposterior and lateral $30^{\circ}$ plain radiographs taken at the time of, or within six months of, aspiration were obtained in all OA patients. Joint space narrowing and osteophyte formation were each scored $0-3$ in each of the three compartments, using an atlas. ${ }^{23}$ A summated score $(0-18)$ was calculated for each knee.

Patients with rheumatoid arthritis (RA) fulfilling American College of Rheumatology criteria $^{24}$ and with symptomatic knee involvement were also studied. Synovial fluid was also obtained from two patients during episodes of acute pseudogout (self limiting florid acute synovitis with calcium pyrophosphate crystals demonstrated in synovial fluid, resolving completely within three weeks).

In all patients (OA subsets, RA, pseudogout) clinical inflammation of the knee at the time of aspiration was designated active (score 4-6) or inactive (score $0-2$ ) using a summated score of six clinical parameters. ${ }^{25}$

\section{SAMPLE COLLECTION}

Knees were aspirated to apparent dryness via a medial approach, and the aspirated volume recorded. A small sample was examined for the presence of crystals and the remainder collected into sterile plastic containers on ice, centrifuged at $2500 \mathrm{~g}$ for 15 minutes at $4^{\circ} \mathrm{C}$ to remove cells and crystals, and the resulting supernatant stored frozen at $-80^{\circ} \mathrm{C}$.

MEASUREMENT OF PAI-1 ANTIGEN, PAI-2 ANTIGEN, UPA ANTIGEN, AND UPAR ANTIGEN BY ENZYME LINKED IMMUNOSORBENT ASSAY (ELISA)

Imubind ELISA kits (American Diagnostica Inc) were used. Absorbances were read on a Dynatech MR5000 plate reader, using BioLinx software. The kits detected active, inactive, and complexed forms of each antigen. The lower limits of detection were $1 \mathrm{ng} / \mathrm{ml}$ PAI-1, $50 \mathrm{pg} / \mathrm{ml} \mathrm{PAI}-2,10 \mathrm{pg} / \mathrm{ml} \mathrm{uPA}$, and $0 \cdot 1 \mathrm{ng} / \mathrm{ml}$ uPAR.

\section{MEASUREMENT OF TPA ANTIGEN BY ELISA}

A Chromogenix Coaliza kit (supplied by Quadratech) was used. Absorbances were read on a Dynatech MR5000 plate reader, using BioLinx software. The lower limit of detection of the assay was $0.5 \mathrm{ng} / \mathrm{ml} \mathrm{tPA}$.

\section{MOLECULAR WEIGHT CHARACTERISATION OF} PLASMINOGEN ACTIVATORS BY SODIUM DODECYL SULPHATE-POLYACRYLAMIDE GEL ELECTROPHORESIS (SDS-PAGE)

SDS-PAGE was carried out according to the method of Roche et al. ${ }^{26} \mathrm{~A} 4 \%$ (w/v) acrylamide stacking gel and $9 \%(w / v)$ resolving gel were used. Two gels were run in parallel, one of the resolving gels containing casein $1 \mathrm{mg} / \mathrm{ml}$ and human plasminogen $5 \mu \mathrm{g} / \mathrm{ml}$ and the other containing casein only, to show that the activity seen was plasminogen dependent. Samples for electrophoresis were diluted in $0.5 \mathrm{~mol} / 1$ Tris/ $\mathrm{HCl}$ (pH 6.8) containing $10 \%(\mathrm{w} / \mathrm{v})$ SDS, $32 \%(v / v)$ glycerol, and $0.5 \%(v / v)$ bromophenol blue, and were applied to gels without boiling. Synovial fluid samples were diluted 1 in 2 and had $5 \mu \mathrm{g}$ cyanogen bromide digested fibrinogen fragments added as tPA stimulator. Prestained standards covered the molecular weight range 36000-198000. Gels were run overnight and then washed in $2.5 \%(\mathrm{v} / \mathrm{v})$ aqueous Triton $\mathrm{X}-100$ for one hour to remove the SDS. For development of plasminogen activator bands, the gels were incubated at $37^{\circ} \mathrm{C}$ for 24 hours in $0.1 \mathrm{~mol} / 1$ Tris- $\mathrm{HCl}$ (pH 8.1). Staining was with Coomassie 
brilliant blue R250. Plasminogen activator activity appeared as clear bands against a dark background where plasminogen activators had converted plasminogen to plasmin and the plasmin had degraded the casein in the gel.

STATISTICAL ANALYSIS

Comparison between disease groups was by the Mann-Whitney $U$ test with a Bonferroni correction. Correlations were calculated using Spearman's correlation coefficient.

\section{Results}

PATIENT CHARACTERISTICS

The table shows details of the patients studied. Although a good age range was obtained in normal subjects, their mean age was lower than that of patients in all the disease groups $(p<0.05)$. Minor differences in radiographic scores were noted in the OA subsets: osteophyte formation and joint space narrowing were significantly lower in OA than in CPA $(\mathrm{p}<0.01, \mathrm{p}<0.05$, respectively).

\section{UPA ANTIGEN CONCENTRATIONS IN SYNOVIAL} FLUID

uPA concentration was significantly greater in the RA group (median $3.11 \mathrm{ng} / \mathrm{ml}$ ) than in the OA (median $1.34 \mathrm{ng} / \mathrm{ml}$ ) and normal (median $0.73 \mathrm{ng} / \mathrm{ml})$ groups $(\mathrm{p}<0.001)$. Patients with $O A$ had significantly greater concentrations of uPA than normal subjects $(p<0.001$ ) (fig 1A). The two samples from patients with pseudogout had uPA concentrations similar to those in patients with $\mathrm{RA}$ $(1.48 \mathrm{ng} / \mathrm{ml}$ and $3.69 \mathrm{ng} / \mathrm{ml})$. The CPA and NGOA groups had significantly smaller uPA concentrations than the OA group $(p<0.001)$ (fig 1B).

\section{TPA ANTIGEN CONCENTRATIONS IN SYNOVIAI}

FLUID

Patients with RA had significantly greater tPA concentrations (median $3.94 \mathrm{ng} / \mathrm{ml}$ ) than those with OA (median $1.63 \mathrm{ng} / \mathrm{ml}$ ) and normal subjects (median $1.28 \mathrm{ng} / \mathrm{ml})(\mathrm{p}<0.001)$, and the concentration in those with OA was significantly greater than that in normal subjects $(p<0.001)$ (fig 2A). The samples from patients with pseudogout had concentrations of tPA similar to those in patients with RA $(2.35 \mathrm{ng} / \mathrm{ml}$ and $4.76 \mathrm{ng} / \mathrm{ml})$. Concentrations of tPA in patients with NGOA were significantly smaller than those in patients with $O A$ (p<0.001) (fig 2B).
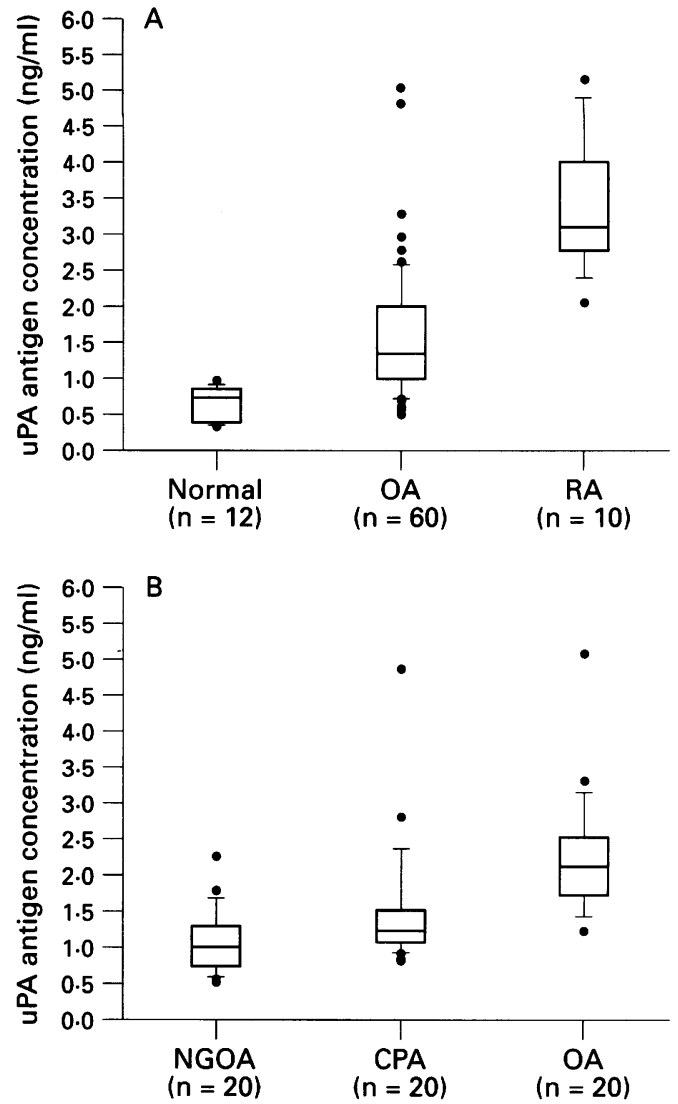

Figure 1 Comparison of urokinase-type plasminogen activator ( $U P A)$ antigen concentration between disease groups $(\boldsymbol{A})$ in normal, osteoarthritis $(O A)$, and rheumatoid arthritis $(R A)$ subjects, and $(B)$ in subclasses of $O A$. Central solid line = median; box $=$ middle $50 \%$ of the data; error bar cap lines $=10$ th and 90 th centiles. Dots represent individual data points outside the 10th and 90th centiles. NGOA= Nodal generalised $O A ; C P A=$ chronic pyrophosphate arthropathy; $O A=$ pauciarticular, large joint $O A$.

\section{UPAR ANTIGEN CONCENTRATIONS IN SYNOVIAL} FLUID

The concentration of uPAR was significantly greater in patients with RA (median $14.2 \mathrm{ng} / \mathrm{ml}$ ) than in those with OA (median $4.33 \mathrm{ng} / \mathrm{ml}$ ) and normal subjects (median $0.95 \mathrm{ng} / \mathrm{ml})(\mathrm{p}<0.001)$, and the concentration in patients with $\mathrm{OA}$ was significantly greater than that in normal subjects $(p<0.001)$ (fig $3 A)$. The samples from patients with pseudogout had UPAR concentrations similar to those in RA patients $(11.23 \mathrm{ng} / \mathrm{ml}$ and $19 \cdot 2 \mathrm{ng} / \mathrm{ml})$. Those in the NGOA subgroup had significantly smaller uPAR concentrations than those in the CPA subgroup ( $p<0.01$ ) (fig $3 B$ ).

PAI-1 ANTIGEN CONCENTRATIONS IN SYNOVIAL FLUID

Patients with RA had significantly greater PAI1 concentrations (median $117.53 \mathrm{ng} / \mathrm{ml}$ ) than

Patient characteristics

\begin{tabular}{lllllll}
\hline $\begin{array}{l}\text { Patient } \\
\text { group }\end{array}$ & $\begin{array}{l}\text { Number of } \\
\text { patients }\end{array}$ & $\begin{array}{l}\text { Number } \\
\text { of knees }\end{array}$ & Sex (M:F) & $\begin{array}{l}\text { Age } \\
(y r)\end{array}$ & $\begin{array}{l}\text { Osteophyte } \\
\text { formation }\end{array}$ & $\begin{array}{l}\text { Foint space } \\
\text { narrowing }\end{array}$ \\
\hline RA & 13 & 17 & $4: 9$ & $60(30-85)$ & - & - \\
Normal & 24 & 26 & $9: 15$ & $39(21-81)$ & - & - \\
OA & 22 & 31 & $13: 9$ & $71(41-88)$ & $4 \cdot 0(0 \cdot 38)$ & $3 \cdot 59(0 \cdot 22)$ \\
CPA & 15 & 20 & $11: 4$ & $72(59-88)$ & $5 \cdot 8(0 \cdot 44)$ & $4 \cdot 7(0 \cdot 36)$ \\
NGOA & 16 & 20 & $2: 14$ & $75(63-87)$ & $5 \cdot 33(0 \cdot 46)$ & $4 \cdot 39(0 \cdot 35)$ \\
\hline
\end{tabular}

Values are mean (range) or mean (SEM)

$\mathrm{RA}=$ Rheumatoid arthritis; $\mathrm{OA}=$ osteoarthritis; $\mathrm{CPA}=$ chronic pyrophosphate arthropathy $\mathrm{NGOA}=$ nodal generalised $\mathrm{OA}$ 

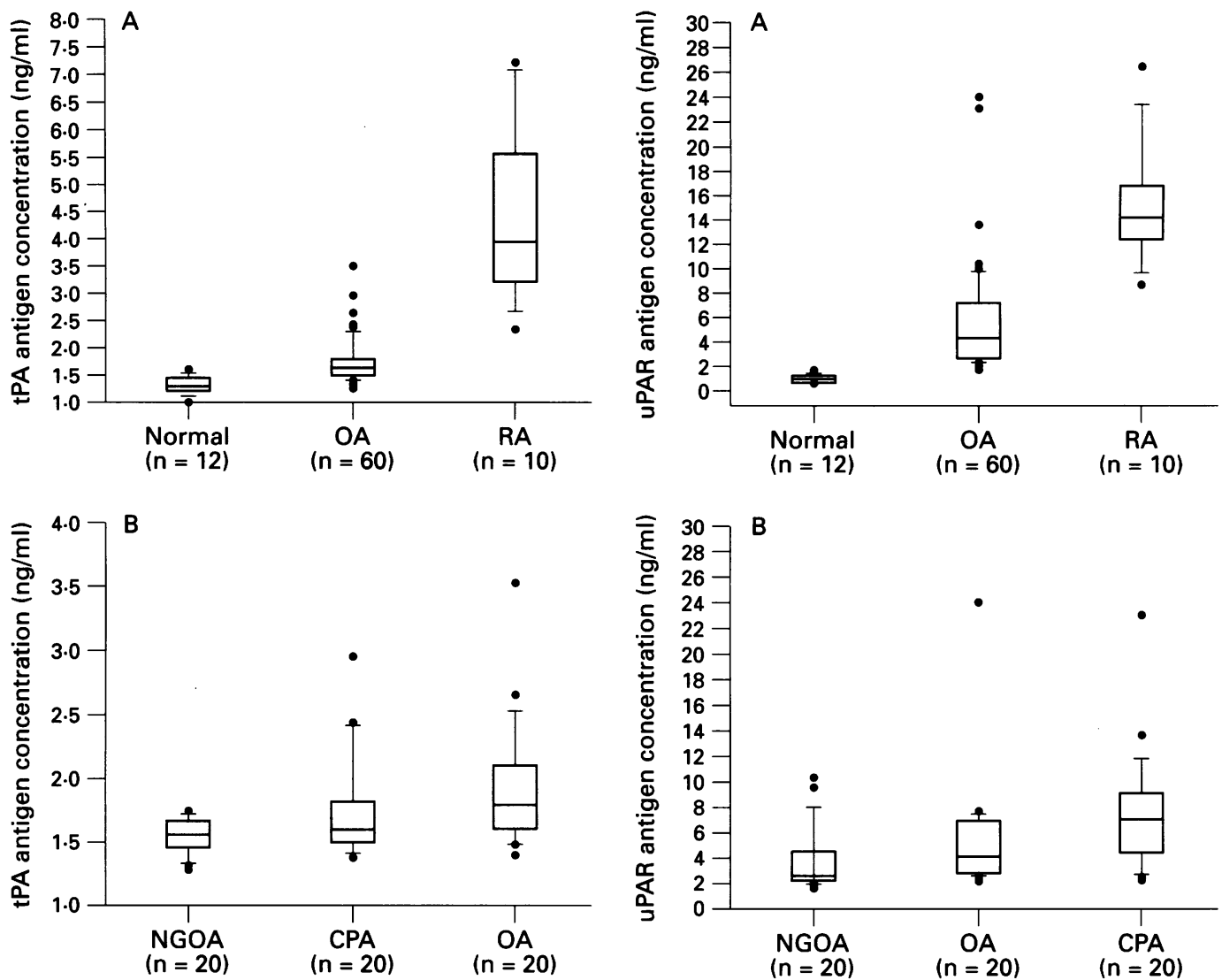

Figure 2 Comparison of tissue-type plasminogen activator (tPA) antigen concentration between disease groups $(\boldsymbol{A})$ in normal, $O A$, and $R A$ subjects, and $(B)$ in subclasses of $O A$. Central solid line = median; box $=$ middle $50 \%$ of the data; error bar cap lines $=10$ th and 90th centiles. Dots represent individual data points outside the 10th and 90th centiles. Abbreviations as in figure 1.

those with OA (median $65.84 \mathrm{ng} / \mathrm{ml}$ ) and normal subjects (median $27.8 \mathrm{ng} / \mathrm{ml})(\mathrm{p}<0.01)$, and those with $O A$ had significantly greater PAI-1 concentrations than normal subjects $(p<0.001)$ (fig 4). Samples from patients with pseudogout had PAI-1 concentrations similar to those with RA $(68.59 \mathrm{ng} / \mathrm{ml}$ and $186 \cdot 52 \mathrm{ng} / \mathrm{ml}$ ).

PAI-2 ANTIGEN CONCENTRATIONS IN SYNOVIAL FLUID

PAI-2 was undetectable in 12 samples from normal individuals, was detectable in only seven of $20 \mathrm{OA}$ samples (median $1.05 \mathrm{ng} / \mathrm{ml}$ ), and was detected in all RA samples (median $7 \cdot 98 \mathrm{ng} / \mathrm{ml})$.

EFFECT OF CLINICALLY ASSESSED INFLAMMATION ON PA/PAI PARAMETERS There were no differences between active (inflamed) and inactive (uninflamed) samples for all parameters measured.

EFFECT OF AGE ON PA/PAI PARAMETERS

None of the parameters measured showed a significant correlation with age in normal subjects.

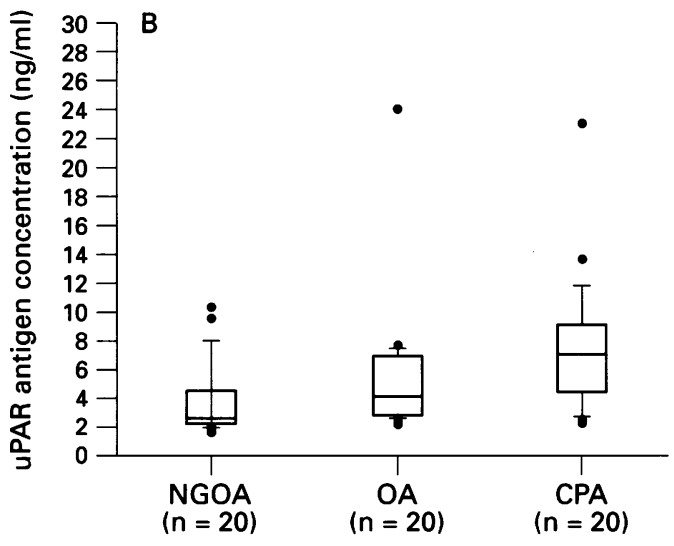

Figure 3 Comparison of urokinase-type plasminogen activator receptor ( $U P A R$ ) antigen concentration between disease groups $(\boldsymbol{A})$ in normal, $O A$, and $R A$ subjects, and $(B)$ in subclasses of $O A$. Central solid line = median; box $=$ middle $50 \%$ of the data; error bar cap lines $=10$ th and 90th centiles. Dots represent individual data points outside the 10th and 90th centiles. Abbreviations as in figure 1 .

CORRELATIONS BETWEEN PA AND PAI PARAMETERS

All parameters measured (uPA, tPA, PAI-1, PAI-2, and UPAR) were increased in parallel, with Spearman's correlation coefficient ranging from 0.63 to 0.82 ( $p$ values $0.001-0.05$ ), demonstrating that the antigen concentrations do not vary in isolation.

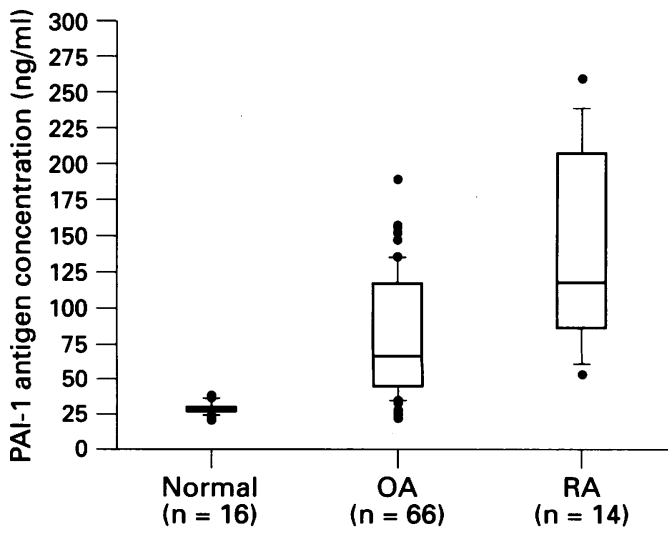

Figure 4 Comparison of plasminogen activator inhibitor-1 (PAI-1) antigen concentration between disease groups. Central solid line $=$ median; box $=$ middle $50 \%$ of the data; error bar cap lines $=10$ th and 90 th centiles. Dots represent individual data points outside the 10th and 90th centiles. Abbreviations as in figure 1. 
CHARACTERISATION OF PLASMINOGEN ACTIVATORS BY SDS-PAGE

SDS-PAGE performed on synovial fluid from different disease groups revealed similar patterns of enzymes in all groups. Intensities of bands varied between disease groups, but PA species did not (fig 5). A band produced at apparent $M_{\mathrm{r}} \approx 42000$ did not appear in the absence of plasminogen, identifying it as a PA. This species comigrated with a standard uPA sample, suggesting identity with uPA. However, a doublet produced at apparent $M_{\mathrm{r}} \approx 91000$ and 98000 appeared on both plasminogen containing and control gels. These enzymes would appear not to be PAs, and their identity remains uncertain; however, they are probably not metalloproteases, because development of the bands could not be inhibited by $1 \mathrm{mmol} / \mathrm{l}$ EDTA.

\section{Discussion}

This is the first study to examine PA and PAI parameters, including uPA receptor concentration, in normal human synovial fluid, and to determine the effect of age on these parameters. It is also the first study to investigate possible differences in concentrations of $\mathrm{PA} / \mathrm{PAI}$ antigens in OA subsets. As a group, the normal subjects were younger than the $O A$ and RA patients. However, no correlation between PA/PAI parameters and age was seen within the broad range of the normal group, so age alone is unlikely to account for the differences observed between the disease groups.

Differences in antigen concentrations between RA patients, OA patients (including subclasses), and normal subjects were consistent. Concentrations in synovial fluid from RA patients were significantly greater than those in $\mathrm{OA}$, and those in synovial fluid from $\mathrm{OA}$ patients were significantly greater than those in normal synovial fluid. tPA antigen concentrations in all groups were within the normal

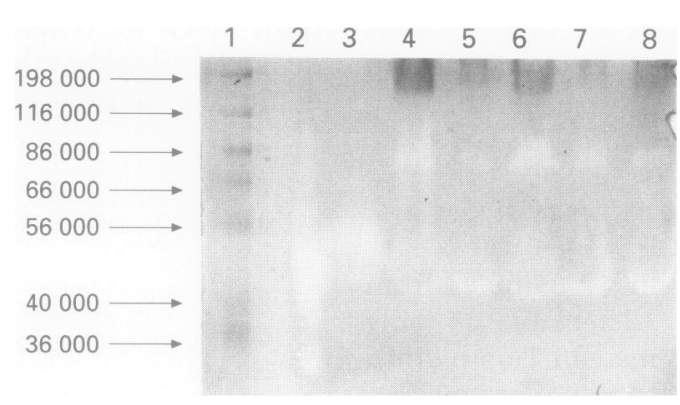

Figure 5 Electrophoretic separation of plasminogen activator species present in synovial fluid from patients in different disease groups, on sodium dodecyl sulphate-polyacrylamide gel containing plasminogen and casein. LANE 1: prestained molecular weight markers; LANE 2: urokinase-type

plasminogen activator (UPA) standard (high molecular weight) at a concentration of $6 \cdot 25 \mathrm{U} / \mathrm{ml}$ (approximately

$78 \mathrm{ng} / \mathrm{ml}$ ); LANE 3: tissue-type plasminogen activator

( $t P A)$ standard (Bowes melanoma, two chain) at a

concentration of $6.25 \mathrm{U} / \mathrm{ml}$ (approximately $9.5 \mathrm{ng} / \mathrm{ml}$ );

LANE 4: pseudogout synovial fluid (estimated

$u P A=1.48 \mathrm{ng} / \mathrm{ml} ; \mathrm{tPA}=2.35 \mathrm{ng} / \mathrm{ml}) ;$ LANE 5: normal

synovial fluid (estimated uPA not measured;

tPA $=1.61 \mathrm{ng} / \mathrm{ml}$ ); LANE 6: RA synovial fluid (estimated

$u P A=3.12 \mathrm{ng} / \mathrm{ml} ; \mathrm{tPA} 3.73 \mathrm{ng} / \mathrm{ml}) ;$ LANE 7: NGOA

synovial fluid (estimated $u P A=1.01 \mathrm{ng} / \mathrm{ml}$;

$t P A=1.68 \mathrm{ng} / \mathrm{ml}) ; L A N E$ 8: $O A$ synovial fluid

(PA estimations not done). plasma range of $1-12 \mathrm{ng} / \mathrm{ml}$. This supports previous reports of tPA in very small concentrations in synovial fluid, mainly from patients with RA. ${ }^{20} 22{ }^{27}$ Cytokine stimulated chondrocytes and endothelial cells are potential sources of tPA in these joints. ${ }^{28} 29$

uPA has been identified as the predominant synovial fluid PA in joint disease. ${ }^{20}{ }^{22}{ }^{30}$ In our study, concentrations of uPA found in OA and RA joints were greater than the normal plasma values of $<1 \mathrm{ng} / \mathrm{ml}$, agreeing with previous findings. 22270 This suggests that cells within the joint, both resident and inflammatory, may be a source of uPA. UPA is a product of chondrocytes, synovial cells, monocytes, and polymorphonuclear leucocytes; ${ }^{28}$ 31-33 greater concentrations of UPA in RA may thus reflect an increase in inflammatory cells in the joint and increased cellular activation by cytokines. ${ }^{22} 32$

In plasma, uPAR concentrations are less than $0 \cdot 1 \mathrm{ng} / \mathrm{ml} .^{34}$ Concentrations in synovial fluid are greater than this, in both normal and diseased joints. Shedding of uPARs may represent a mechanism of control of uPA activity, the soluble receptors competing with cell surface receptors for uPA binding, and thus limiting cell surface plasminogen activation. Increased concentrations of cytokines such as tumour necrosis factor in inflamed joints may increase expression and, perhaps, shedding of receptors. ${ }^{17}$

PAI-1 concentrations remained in the normal plasma range of $4-43 \mathrm{ng} / \mathrm{ml}$ in normal synovial fluid, but were increased in diseased joints. Brommer et $a l^{30}$ found that PAI-1 concentrations in synovial fluid from patients with RA were greater than in those in normal plasma, but Saxne $e t a l^{22}$ found concentrations in synovial fluid from patients with RA and OA to be within the normal plasma range. PAI-1 can be produced by a number of cell types in the joint. ${ }^{211}{ }^{12}$ Increased concentrations in RA may be the result of increased cytokine concentrations. ${ }^{32}$ However, cytokines may have differential effects on PAI-1 production in different cell types: for example, IL-1 increases PAI-1 in endothelial cells, but decreases it in chondrocytes and synovial cells. ${ }^{11} 1235$ Such effects may give rise to variability in PAI- 1 concentrations in different patients.

PAI-2 was undetectable in normal synovial fluid and concentrations in $\mathrm{OA}$ were close to the limit of detection of the assay; however, it was detected in all synovial fluid samples from RA patients. This is in agreement with the findings of other workers. ${ }^{22}$ Increased PAI-2 concentration may be an index of infiltration of the joint by inflammatory cells, as these are a major source. ${ }^{222}$ In addition, IL-1 stimulates PAI-2 production in synovial fibroblasts. ${ }^{12}$ An increase in PAI concentration may indicate an attempt to maintain the PA/PAI balance in joint disease.

When our OA group was subdivided into three subsets, results varied. The NGOA subset appeared to differ for uPA antigen, tPA antigen, and UPAR antigen, while the CPA subset showed a difference only for UPA antigen and uPAR antigen. Such differences support 
differentiation between NGOA and other forms of OA, with possible differences in pathogenesis. Measurement of other biochemical markers in subsets of OA would therefore be of interest.

For all antigen concentrations, samples from patients with pseudogout had values similar to those from patients with RA. This may indicate some link between PA/PAI parameters and florid inflammation. However, none of the antigen concentrations showed a difference between active and inactive disease samples. This could reflect insensitivity of the clinical assessment of inflammation, though clear correlation between complement activation and this clinical score ${ }^{25}$ would argue against this. It may be, therefore, that the greater concentrations observed in RA and pseudogout relate to qualitative rather than quantitative differences in inflammation.

All antigen concentrations were increased in parallel, that of no one antigen varying in isolation. This would suggest an upregulation of the entire PA/PAI system. As PA concentrations increased, PAI concentrations also increased, perhaps reflecting a mechanism to neutralise any increased enzyme activity. However, there may still be an increase in the direct and indirect effects that the PA system has on extracellular matrix degradation. This, in turn, could affect the pathophysiology of RA and OA.

The presence of tPA was difficult to demonstrate in our study. tPA activity on the gels may have been masked by the doublet banding that occurred at $M_{\mathrm{r}} \approx 91-98000$ in both control and plasminogen containing gels. Alternatively, this doublet may represent tPA, as other workers have shown that tPA from synovial fluid runs at $M_{\mathrm{r}} \approx 90000$-possibly the result of association with other proteins in synovial fluid. ${ }^{21} 36$ The occurrence of a similar doublet in the control gel could be the result of activation of plasminogen, derived from synovial fluid, which runs close to tPA on the gel. ${ }^{36}$ However, spiking of synovial fluid with tPA did not produce additional bands of lysis, perhaps suggesting degradation of tPA by other proteolytic enzymes in synovial fluid. Combination of tPA with PAIs would have produced additional bands of lysis, $M_{\mathrm{r}} \approx 100000$ corresponding to enzyme-inhibitor complexes, as described by Levin. ${ }^{29}$ The identity of lysis bands could be confirmed by immunoprecipitation of samples before electrophoresis, using antibodies to tPA or UPA.

Our findings comparing concentrations of PAs and PAIs in synovial fluid from patients with RA and OA are broadly in agreement with those of other workers. ${ }^{22}{ }^{27}{ }^{30}$ However, we were also able to compare these values with those in normal synovial fluid, and to measure UPAR concentrations. The increased concentrations of PA/PAI parameters in OA compared with normal indicate that it is not valid to use OA as a surrogate control in this type of study. Our data also confirm that alterations in the PA/PAI system occur in both OA and RA, and these may contribute to the pathophysiology of these diseases.
This work was funded by the Arthritis and Rheumatism Council, to whom we are indebted.

1 Dano K, Andreason P, Grondahl-Hansen J, Kristensen P, Neilson L S, Skriver L. Plasminogen activators, tissue degradation and cancer. Adv Cancer Res 1985; 44: degrada

2 Hart D A, Rehemtulla A. Plasminogen activators and their inhibitors: regulators of extracellular proteolysis and cell function. Comp Biochem Physiol 1988; 90B: 691-708.

3 Fairbairn S, Gilbert R, Ojakian G, Schwimmer $R$, Quigley J. The extracellular matrix of normal chick embryo fibroblasts: its effect on transformed chick fibroblasts and its proteolytic degradation by transformants. 千 Cell Biol 1985; 101: 1790-8.

4 Mochan E, Keler T. Plasmin degradation of cartilage proteoglycan. Biochim Biophys Acta 1984; 800: 312-5.

5 Lack C H, Rogers H J. Action of plasmin on cartilage. Nature 1958; 182: 948-9.

6 Pelletier J-P, Martel-Pelletier J, Howell D S, GhanderMnaymneh L, Emis J E, Woessner J F Jr. Collagenase and Mnaymneh L, Emis J E, Woessner J F Jr. Collagenase and collagenolytic activity in human

7 Collier S, Ghosh P. The role of plasminogen in interleukin-1 mediated cartilage degradation. $\mathcal{F}$ Rheumatol 1988; 15 1129-37.

8 Werb Z, Mainardi C L, Vater C A, Harris E D Jr. Endogenous activators of latent collagenase by rheumatoid synovial cells. Evidence for a role of plasminogen activator. $N$ Engl f Med 1977; 296: 1017-23.

9 Kruithof E K O, Tran-Thang C, Ransjin A, Bachmann F. Demonstration of a fast acting inhibitor of plasminogen activators in human plasma. Blood 1984; 64: 907-13.

10 Knudsen B, Harpel P C, Nachman R L. Plasminogen activator inhibitor is associated with extracellular matrix of cultured bovine smooth muscle cells. $\mathcal{f}$ Clin Invest 1987; 80: 1082-9.

11 Campbell I K, Last K, Novak U, Lund L R, Hamilton J A. Recombinant human interleukin-1 inhibits plasminogen activator inhibitor-1 (PAI-1) production by human articular cartilage and chondrocytes. Biochem Biophys Re Commun 1991; 174: 251-7.

12 Hamilton J A, Cheung D, Filonz E L, et al. Independent regulation of plasminogen activator inhibitor 2 and plasminogen activator inhibitor 1 in human synovia fibroblasts. Arthritis Rheum 1992; 35: 1526-34.

13 Martel-Pelletier J, Zarfarullah M, Kodama S, Pelletier J-P. In vitro effects of interleukin 1 on the synthesis of metalloproteinases, TIMP, plasminogen activators and their inhibitors in human cartilage. $\mathcal{F}$ Rheumatol 1991; 18 (suppl 27): 80-4.

14 Vassalli J D, Baccino D, Belin D. A cellular binding site for the Mr 55,000 form of human urokinase plasminogen activator. $f$ Cell Biol 1985; 100: 86-92.

15 Blasi F. Urokinase and urokinase receptor: a paracrine/ autocrine system regulating cell migration and invasiveness. Bioessays 1993; 15: 105-11.

16 Martel-Pelletier J, Faure M-P, McCollum R, Mineau F Cloutier J-M, Pelletier J P. Plasmin, plasminogen activators and inhibitor in human osteoarthritic cartilage. F Rheumatol 1991; 18: 1863-71.

17 Kirchheimer J C, Nong Y-H, Remold H G. IFN- $\gamma$, tumour necrosis factor- $\alpha$ and urokinase regulate the expression of urokinase receptors on human monocytes. 7 Immunol 1988; 141: 4229-34.

18 Del Rosso M, Fibbi G, Magnelli L, et al. Modulation of urokinase receptors on human synovial cells and osteourokinase receptors on human synovial cells and osteo1990; 12: 91-100.

19 Kirchheimer J, Remold H G, Wanivenhaus A, Binder B R. Increased proteolytic activity on the surface of monocytes from patients with rheumatoid arthritis. Arthritis Rheum 1991; 34: 1430-3.

20 Mochan E, Uhl J. Elevations in synovial fluid plasminogen activator in patients with rheumatoid arthritis. $\mathcal{F}$ Rheumatol 1984; 11: 123-8.

21 Kikuchi H, Tanaka S, Matsuo O. Plasminogen activator in synovial fluid from patients with rheumatoid arthritis. fRheumatol 1987; 14: 439-45.

22 Saxne T, Lecander I, Geborek P. Plasminogen activators and plasminogen activator inhibitors in synovial fluid. Difference between inflammatory joint disorders and Difference between inflammatory joint

23 Burnett S, Hart D J, Cooper C, Spector T D. A radiographic atlas of osteoarthritis. London: Springer Verlag, 1994.

24 Arnett F C, Edworthy S M, Bloch D A, et al. The American Rheumatism Association 1987 revised criteria for the classification of rheumatoid arthritis. Arthritis Rheum 1988; 31: 315-24.

25 Doherty M, Richards N, Hornby J, Powell R. Relationship between synovial fluid $\mathrm{C} 3$ degradation products and local joint inflammation in rheumatoid arthritis, osteoarthritis and crystal associated arthropathy. Ann Rheum Dis 1988; 47: $190-7$.

26 Roche P C, Campeau J D, Shaw S T. Comparative electrophoretic analysis of human and porcine plasminogen activators in SDS-polyacrylamide gels containing plasminogen and casein. Biochim Biophys Acta 1983; 745 82-9.

27 Kummer J A, Abbink J J, De Boer J-P, et al. Analysis of intraarticular fibrinolytic pathways in patients with inflammatory and non-inflammatory joint diseases. Arthritis Rheum 1992; 35: 884-93. 
28 Bunning $\mathrm{R}$ A D, Crawford A, Richardson $\mathrm{H}$ J, Opdennakker G, Van Damme J, Russell R G G. Interleukin 1 preferentially stimulates the production of tissue-type plasminogen activator by human articular chondrocytes. Biochim Biophys Acta 1987; 924: 473-82.

29 Levin E G. Latent tissue plasminogen activator produced by human endothelial cells in culture: evidence for an enzyme-inhibitor complex. Proc Natl Acad Sci USA 1983; 80: $6804-10$

30 Brommer E J P, Dooijewaard G, Dijkmans B A C Breedveld F C. Plasminogen activators in synovial fluid and plasma from patients with arthritis. Ann Rheum Dis 1992; 51: 965-8.

31 Leizer T, Hamilton J A. Interleukin- $1 \alpha$ and interleukin- $1 \beta$ stimulate synovial fibroblast plasminogen activator activity. Arthritis Rheum 1987; 30: 562-6.

32 Hamilton J A, Hart P H, Leizer T, Vitti G F, Campbell I K. Regulation of plasminogen activator activity in arthritic joints. $¥$ Rheumatol 1991 ; 18 (suppl 27): 106-9.
33 Heiple J M, Ossowski L. Human neutrophil plasminogen activator is localised in specific granules and is trans-
located to the cell surface by exocytosis. $\mathcal{F}$ Exp Med 1986; 164: 826-40.

34 Ronne E, Pappot H, Grondahl-Hansen J, et al. The receptor for urokinase plasminogen activator is present in plasma from healthy donors and elevated in patients with paroxysmal nocturnal haemoglobinuria. $\mathrm{Br} \mathcal{F}$ Haematol 1995; 89: 576-81.

35 Nachman R L, Hajjar K A, Silverstein R L, Dinarello C A. Interleukin 1 induces endothelial cell synthesis of plasminogen activator inhibitor. $\mathcal{f} \operatorname{Exp} M e d$ 1986; 163 1595-600.

36 Lindenhayn $\mathrm{K}$, Heilmann $\mathrm{H}-\mathrm{H}$, Regling $\mathrm{G}$, Haupt $\mathrm{R}$. Die plasminogenaktivator-aktivitat der synovialflussigkeit als indikator fur aktivierungsphanomene bei degenerativen gelenkerkrankungen. $Z$ Rheumatol 1989; 48: 246-53. 